\title{
Quantitative significance of measuring trimethylselenonium in urine for assessing chronically high intakes of selenium in human subjects $\dagger$
}

\author{
M. Janghorbani ${ }^{1}$, Y. Xia ${ }^{2}$, P. $\mathrm{Ha}^{2}$, P. D. Whanger ${ }^{3}$, J. A. Butler ${ }^{3}$, J. W. Olesik ${ }^{4}$ and L. Daniels ${ }^{4}$ \\ ${ }^{1}$ BioChemAnalysis Corp. and the Center for Stable Isotope Research Inc., 2201 West Campbell Park Drive, Chicago, IL, USA \\ ${ }^{2}$ Chinese Academy of Preventive Medicine, Institute of Nutrition and Food Hygiene, Beijing, People's Republic of China \\ ${ }^{3}$ Department of Agricultural Chemistry, Oregon State University, Corvallis, OR 97331, USA \\ ${ }^{4}$ Microscopic and Chemical Analysis Research Center, Ohio State University, Columbus, OH, USA
}

(Received 18 August 1998 - Revised 31 March 1999 - Accepted 25 May 1999)

\begin{abstract}
The purpose of the present study was to investigate the effects of Se restriction on the excretion of Se in men who had consumed high levels of this element during their entire lives. With the use of stable isotopes of Se as selenite, the excretion of methylated Se in urine was investigated in Chinese men ( $n$ 10) who had habitual chronic high intakes of this element. The relationship between either urine Se or trimethylselenonium (TMSe) to the estimated long-term Se intake was not linear over the entire range of intake, which was also true for the infusion of labelled selenite. A non-linear relationship was also found between urine TMSe and urine Se both for TMSe arising from catabolism of endogenous body Se and that from infused selenite. The data suggest a close precursor-product relationship of urine Se and its TMSe component based on the nearly identical specific activities for these two selenocompounds. Although dimethylselenide in breath was not measured in the present study, combining urinary TMSe with this breath test may be more useful in the assessment of long-term Se status.
\end{abstract}

Selenium: Chinese men: Urine: Stable isotopes

Little accurate information is available on the relationship between long-term Se intake in different chemical forms, the resultant body status of Se, and potential indices that could be used to monitor Se status. The ability to monitor Se status during long-term supplementation is important because of the need to monitor biological efficacy and concerns for toxicity. Since much of total body Se is present as selenomethionine (Semet) in body proteins (Sunde, 1990), measurement of an index related to total body Se would not be useful as the required index. In contrast, an index related quantitatively to whole body flux of $\mathrm{Se}^{2-}$ (Fig. 1) may provide the needed information. Of the various selenocompounds that may be available in human subjects by non-invasive sampling, hair and toenails may be the least useful indicators of body status of biologically active Se because a large fraction of their Se content may be from non-specific incorporation of dietary Semet in their structural proteins (Fig. 1). Of the three selenocompounds present in plasma (Deagen et al. 1993) (albumin-bound Se, glutathione peroxidase (EC 1.11.1.9), and selenoprotein P) albuminbound Se is also not likely to be a useful indicator of body status of biologically active Se because the major portion of its Se has been shown to be in the form of Semet (Deagen et al. 1991), while the Se content of glutathione peroxidase and selenoprotein $\mathrm{P}$ is saturable over the nutritional range of intake (Combs \& Combs, 1986; Burk et al. 1991; Burk \& Hill, 1994) and is not likely to respond to the wide range of Se intake involved in long-term supplementation. On the other hand, both urine Se and its methylated derivative(s) may have potential as quantitatively useful indices of biologically active Se (Ip et al. 1991; Vadhanavikit et al. 1993). However, for either urine Se, or any methylated derivatives excreted in urine to be able to function as quantitative indices of biologically active body Se, their excretion must bear a quantitative relationship to whole body flux of $\mathrm{Se}^{2-}$ over the applicable range of long-term $\mathrm{Se}$ supplementation. In order to understand the relationship between Se status and disposition of $\mathrm{Se}^{2-}$ where the body's capacity for its incorporation has been exceeded, the present investigation was undertaken to study the excretion of trimethylselenonium (TMSe) in men who had consumed excess Se their entire lives. The experimental data presented

\footnotetext{
Abbreviations: SA, specific activity; Semet, selenomethionine; TMSe, trimethylselenonium.

* Corresponding author: Professor P. D. Whanger, fax +1 541737 0497, email phil.whanger@ orst.edu

$\dagger$ Presented at the annual meetings of Experimental Biology 97 and 98 in New Orleans, LA, USA and in San Francisco, CA, USA and published in abstract forms: FASEB Journal (1997) 11, A359 and FASEB Journal (1998) 12, A524. Published with the approval of the Oregon State University Agricultural Experiment Station as Technical paper no. 11, 385.
} 


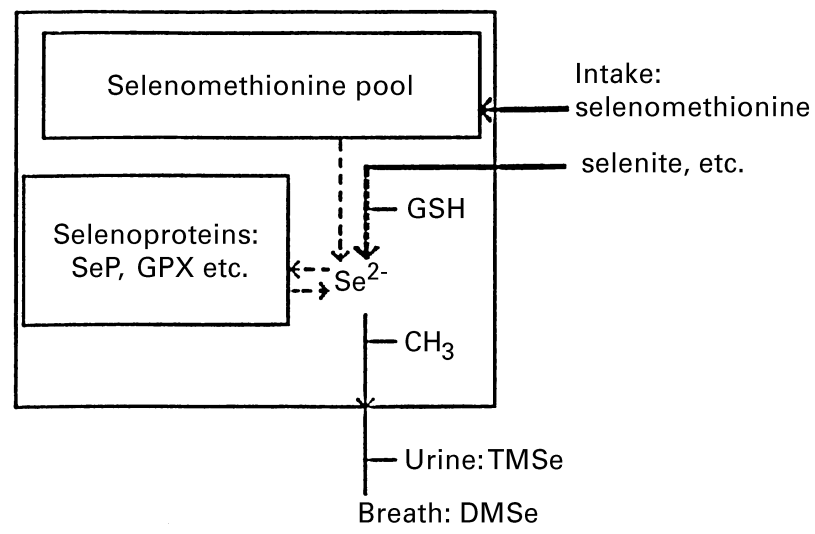

Fig. 1. Simplified scheme of mammalian metabolism of selenium, showing the relationship between selenomethionine-containing proteins, the selenite-exchangeable metabolic pool, and $\mathrm{Se}^{2-}$. SeP, selenoprotein P; GPX, glutathione peroxidase (EC 1.11.1.9); $\mathrm{GSH}$, reduced glutathione; $\mathrm{Se}^{-2}$, selenide; $\mathrm{CH}_{3}$, methyl group; TMSe, trimethylselenonium; DMSe, dimethylselenide.

in this manuscript provide some initial insight into this important relationship.

\section{Experimental methods}

\section{Protocol}

Ten adult male volunteers who had been life-long residents of the village of Luojiaba (Jianshi County, Hubei Province, People's Republic of China; estimated daily Se intake: 197$1230 \mu \mathrm{g} / \mathrm{d}$; Table 1) were recruited for this investigation. A description of the people living in this high-Se area has been presented previously (Xia et al. 1992). The protocol was approved by the Oregon State University Committee for the Protection of Human Subjects and by a special Institutional Review Board convened at the Chinese Academy of Preventive Medicine in Beijing, and the subjects signed informed consent before participation in the study. Each subject was paid an equivalent of US $\$ 300$ for participation in this study. After baseline samples were obtained (day 0), the men were moved to Changping village (Lichuan County, Hubei Province), approximately $300 \mathrm{~km}$ from their native village, where they stayed for $70 \mathrm{~d}$. The latter village is in the Keshan disease area, which during 1969-83 had incidence and mortality rates of 103 per 100000 and $45.2 \%$ respectively. These rates were the highest recorded among villages in Lichuan County for the period. During their $70 \mathrm{~d}$ stay, they consumed locally grown food providing $43.3 \mu \mathrm{g} \mathrm{Se} / \mathrm{d}$ (range $30-45 \mu \mathrm{g} \mathrm{Se} / \mathrm{d}$ ) based on $3 \mathrm{~d}$ dietary survey. Anthropometric and Se baseline data for the subjects are summarized in Table 1.

On day 1 of the protocol, each subject was infused with $105 \mu \mathrm{g}$ Se labelled with the stable isotope ${ }^{74} \mathrm{Se}$ which was prepared specifically for intravenous administration in the form of selenite (see later), by adding the stable isotope solution to a $500 \mathrm{ml}$ bag of intravenous glucose solution $(50 \mathrm{~g} / \mathrm{l})$. Infusion rate was adjusted (by gravity) to last for $5 \mathrm{~h}$ (07.00-12.00 hours). Complete $24 \mathrm{~h}$ urine collections were made daily for the first $7 \mathrm{~d}$ after infusion, and at days 22,43 , and 62 afterwards. An identical infusion procedure was again repeated on day 64 , with the exception that the total amount of Se infused was $113 \mu \mathrm{g}$. Similarly to the first infusion period, $24 \mathrm{~h}$ urine collections were made daily for $7 \mathrm{~d}$ following the second infusion at $64 \mathrm{~d}$. The subjects were closely monitored by the medical and research staff during the course of the investigation.

\section{Preparation of stable isotope for infusion}

Elemental Se $(13.6 \mathrm{mg})$ enriched with respect to ${ }^{74} \mathrm{Se}\left({ }^{74} \mathrm{Se}\right.$ $54.4 \%$ by weight; ${ }^{77} \mathrm{Se} 4.406 \%$ by weight; $\mathrm{R}_{74 / 77} 12.35 \%$ by weight; the corresponding values for unenriched Se were $0.815,7.38$ and $0.110 \%$ respectively) was dissolved in $2-3 \mathrm{ml} 16 \mathrm{M}-\mathrm{HNO}_{3}$. The resulting solution was heated gently until almost dry. The remaining liquid was transferred with deionized water into an acid-washed plastic container and volume adjusted with deionized water. This solution had a concentration of $99.83 \mu \mathrm{g} \mathrm{Se} / \mathrm{ml}$ and $\mathrm{pH}$ of 3.0. A measured portion of this solution was prepared for infusion as follows. Solution $\mathrm{pH}$ was adjusted with $\mathrm{NaOH}$ to 7.40 and diluted with saline solution $(9 \mathrm{~g} / \mathrm{l})$. It was then filtered through a $0.45 \mu \mathrm{m}$ filter and $2.0 \mathrm{ml}$ portions dispensed into sterile glass ampoules. All ampoules were then sterilized by autoclaving at $120^{\circ}$ for $20 \mathrm{~min}$. Three of the ampoules were analysed for Se $(52.5 \mu \mathrm{g} / 2 \mathrm{ml}$ ampoule). Freedom from pyrogenicity was tested in five rabbits with three randomly selected ampoules using standard

Table 1. Anthropometric and baseline selenium variables for the male subjects $(n 10)$

\begin{tabular}{lcccccc}
\hline Subject no. & $\begin{array}{c}\text { Age } \\
(\text { years })\end{array}$ & $\begin{array}{c}\text { Weight } \\
(\mathrm{kg})\end{array}$ & $\begin{array}{c}\text { Packed } \\
\text { cell volume } \\
(\%)\end{array}$ & $\begin{array}{c}\text { Estimated } \\
\text { long-term Se intake* } \\
(\mu \mathrm{g} / \mathrm{d})\end{array}$ & $\begin{array}{c}\text { Urine Se } \\
(\mu \mathrm{g} / \mathrm{d})\end{array}$ & $\begin{array}{c}\text { Plasma Se } \\
(\mathrm{ng} / \mathrm{ml})\end{array}$ \\
\hline 1 & 50 & 67 & $45 \cdot 7$ & 507 & 356 & 379 \\
2 & 45 & 69 & $44 \cdot 4$ & 363 & 199 & 309 \\
3 & 49 & 65 & $47 \cdot 7$ & 439 & 325 & 347 \\
4 & 19 & 59 & $43 \cdot 9$ & 402 & 218 & 329 \\
5 & 44 & 64 & $46 \cdot 2$ & 358 & 255 & 306 \\
6 & 41 & 61 & $45 \cdot 7$ & 348 & 185 & 301 \\
7 & 19 & 57 & $47 \cdot 8$ & 197 & 89 & 212 \\
8 & 25 & 60 & $46 \cdot 2$ & 463 & 270 & 359 \\
9 & 22 & 65 & $47 \cdot 8$ & 492 & 244 & 372 \\
10 & 29 & 71 & $43 \cdot 9$ & 1230 & 433 & 654 \\
\hline
\end{tabular}

* Long-term Se intake was calculated as: $\log ($ Se intake $)=1.624 \log ($ plasma Se $)+3.389$, in which units are $\mu \mathrm{g} / \mathrm{d}$ and $\mu \mathrm{g} / \mathrm{ml}$ for intake and plasma concentrations respectively (Yang et al. 1989). 
procedures. A similar batch was prepared for the second infusion with a final Se concentration of $56.5 \mu \mathrm{g} / 2 \mathrm{ml}$ ampoule.

\section{Analytical procedures}

The volume of each $24 \mathrm{~h}$ urine collection was determined and measured portions were processed for the measurement of total urine Se using $\mathrm{HNO}_{3}-\mathrm{HClO}_{4}$ digestion (Sun et al. 1987). In addition, measured portions of urine were processed for the isolation of TMSe using the previously published KOH-thermolysis procedure (Sun et al. 1987). Each resulting solution was then analysed for Se content by the fluorometric method (Yang et al. 1987) and the ${ }^{74} \mathrm{Se}:{ }^{77} \mathrm{Se}$ isotope ratio $\left(\mathrm{R}_{74 / 77}\right)$ with hydride generation-inductively coupled plasma mass spectrometry (Ting et al. 1989).

\section{Calculations}

Experimental data for each sample for $\mathrm{Se}$ and $\mathrm{R}_{74 / 77}$ were combined to calculate that portion of Se in the sample
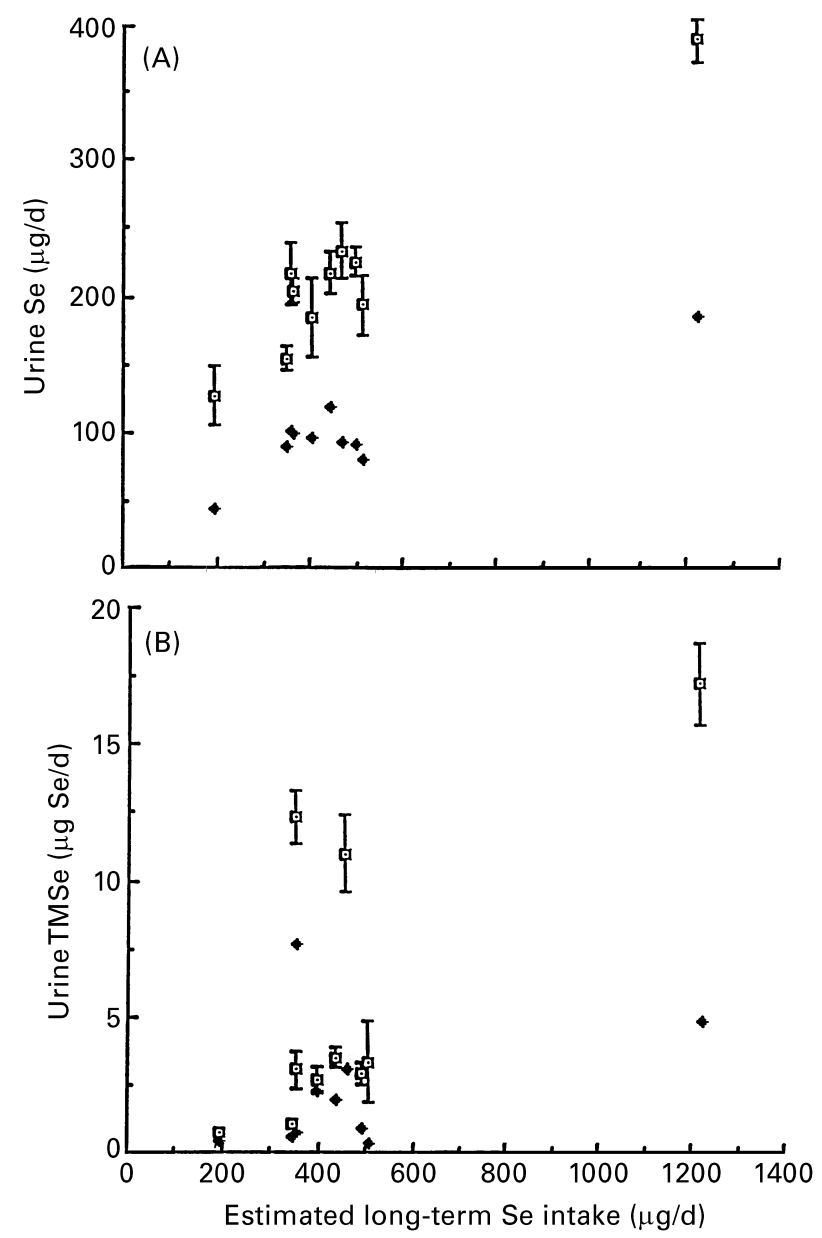

Fig. 2. Relationships between urine selenium (A), or urine trimethylselenonium (TMSe) (B), and the estimated long-term Se intake of the male subjects $(n 10)$. ( $\square$ ), Mean urine variable days 2 to 7 (baseline); $(\downarrow)$, mean urine variable days 22, 43 and 62 following intravenous infusions of $105 \mu \mathrm{g}$ selenium as selenite on day 0 . Values are means with standard errors of the mean represented by vertical bars. originating from the enriched infusate, according to equations 1,2 and 3:

$$
\begin{aligned}
\mathrm{R}_{74 / 77}= & \left({ }^{74} \mathrm{Se}^{\circ}+{ }^{74} \mathrm{Se}^{*}\right) /\left({ }^{77} \mathrm{Se}^{\circ}+{ }^{74} \mathrm{Se}^{*}\right) \\
= & \left(0 \cdot 00814 \mathrm{Se}^{\circ}+0.544 \mathrm{Se}^{*}\right) /\left(0.0738 \mathrm{Se}^{\circ}\right. \\
& \left.+0.0441 \mathrm{Se}^{*}\right),
\end{aligned}
$$

and

$$
\mathrm{Se}^{\circ}=\mathrm{Se}-\mathrm{Se}^{*},
$$

where $\mathrm{R}_{74 / 77}$ is the measured isotope ratio in the sample (on a weight for weight basis), Se is the Se content of sample, measured fluorometrically, $\mathrm{Se}^{\circ}$ is the Se content of sample of unenriched origin, $\mathrm{Se}^{*}$ is the Se content of sample of enriched origin, and the constants are the appropriate weight fractions of each isotope in either unenriched Se, or infusate Se.

Simultaneous solution of equations 1 and 2 yields the desired quantity:

$$
\begin{aligned}
\mathrm{Se}^{*}= & \left(\left(0.0738 \mathrm{R}_{74 / 77}-0.00815\right) \mathrm{Se}\right) /\left(0.02974 \mathrm{R}_{74 / 77}\right. \\
& +0.53585) .
\end{aligned}
$$

\section{Results}

Total Se and TMSe levels were determined in urine from all ten men (Figs. 2, 3 and 4) but stable isotopes of Se as total $\mathrm{Se}^{*}$ and TMSe were determined in urine from only five of these men (Figs. 5 and 6). Since there were no statistical differences between the corresponding available data between the 10-subject universe and the subset of five subjects, the data shown in Figs. 5 and 6 are representative of all the subjects.

\section{Relationship between long-term selenium intake and urine excretion}

Long-term Se intake was estimated from the expression $\log (\mathrm{Se}$ intake $(\mu \mathrm{g} / \mathrm{d}))=1.624 \log ($ plasma Se $(\mu \mathrm{g} / \mathrm{ml}))+$ 3.389 (Yang et al. 1989). The ten subjects of this investigation showed a wide range of long-term Se intake (Table 1), in the range 2-12 times the average long-term intake for North American adults (Levander, 1987). The relationship between the estimated Se intake and urine $\mathrm{Se}$ (or TMSe) excretion is shown in Fig. 2. In Fig. 2(A), we have plotted daily urine excretion as average value ( \pm 1 SEM) for days 2 7 for each subject against his estimated long-term daily intake of Se, as well as the average value for days 22, 43, and 62. As seen from the data of Fig. 3(A), in which the average daily urine excretion of all subjects as a function of time is shown, there was little systematic decrease in daily urine excretion during the first $7 \mathrm{~d}$, but marked decreases thereafter. Thus, we consider average daily urine excretion for days $2-7$ to be a better estimate of the initial endogenous urine excretion than baseline values (day 0). Similar data for urine TMSe are shown in Fig. 2(B) as a function of the estimated long-term intake, and in Fig. 3(B) as a function of time. The average of the ratio in each subject for urine excretion of Se for days 22, 43, and 62 to that for the corresponding value of day 2-7 (Fig. 2(A)) for all subjects 


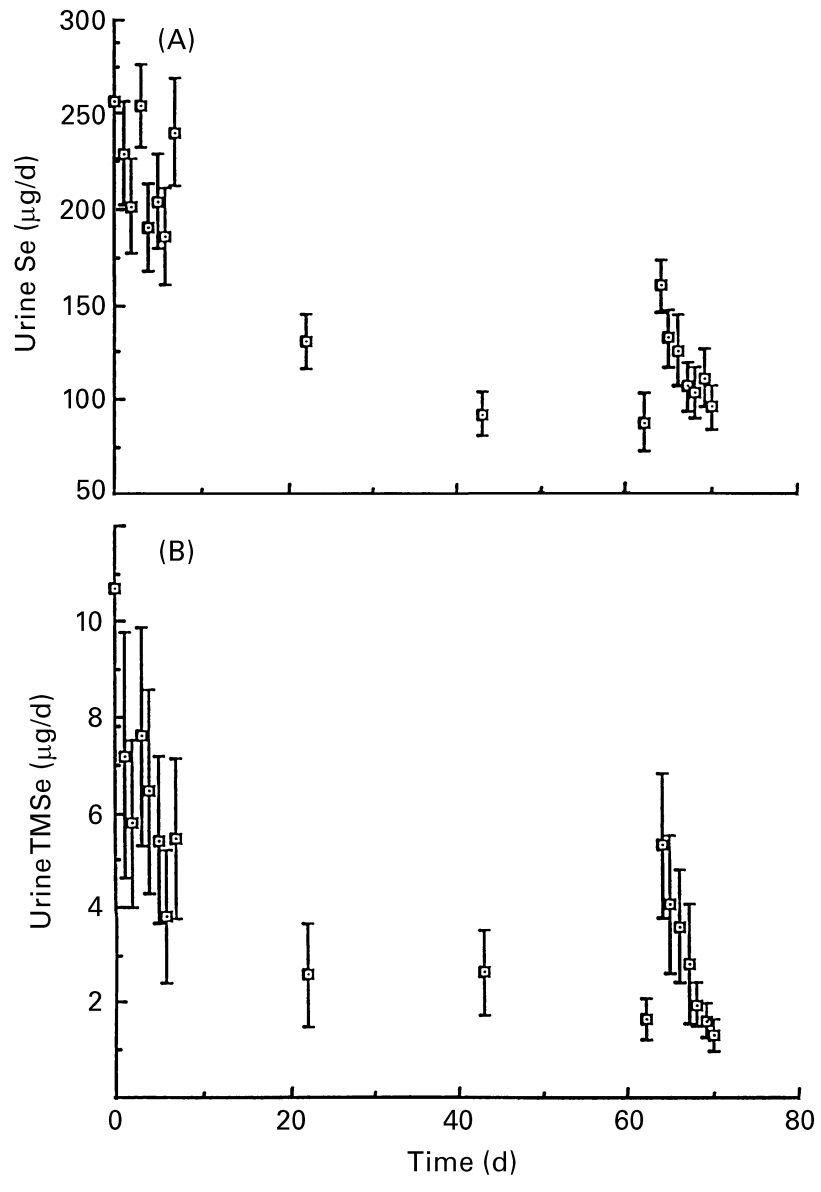

Fig. 3. Time course of urine selenium $(A)$, or urine trimethylselenonium (TMSe) (B) excretion during the experimental period of $70 \mathrm{~d}$ in ten male subjects with long-term high selenium intakes. Subjects were given an intravenous infusion of $105 \mu \mathrm{g}$ selenium as selenite on day 0 , and $113 \mu \mathrm{g}$ Se on day 62 . Values are means with standard errors of the mean represented by vertical bars.

was 0.462 (SEM 0.023) and that for TMSe (Fig. 2(B)) was 0.437 (SEM 0.073). Therefore, during days 22-62 each subject, regardless of his initial body status, lost on average $46.2 \% \mathrm{Se}$ in urine compared with that for days 2-7. Similarly, loss of TMSe decreased to $43.7 \%$ of its initial value.

\section{Relationship between urine selenium and urine trimethylselenonium}

In Fig. 4(A) we have plotted the observed relationship between urine Se and urine TMSe for all urine samples regardless of from whom and when they were collected. In Fig. 4(B), we have presented the data according to the day of collection, and in Fig. 4(C) according to an incremental increase in urine Se content for each $50 \mu \mathrm{g}$ increment. The relatively large inter-individual variations in urine Se (and TMSe), due to large variations in long-term Se intake of the subjects (Table 1), are apparent in Fig. 4(B) and partially mask the non-linear relationship between the two variables as long-term Se intake increases. However, when the data are presented according to incremental increases in urine $\mathrm{Se}$
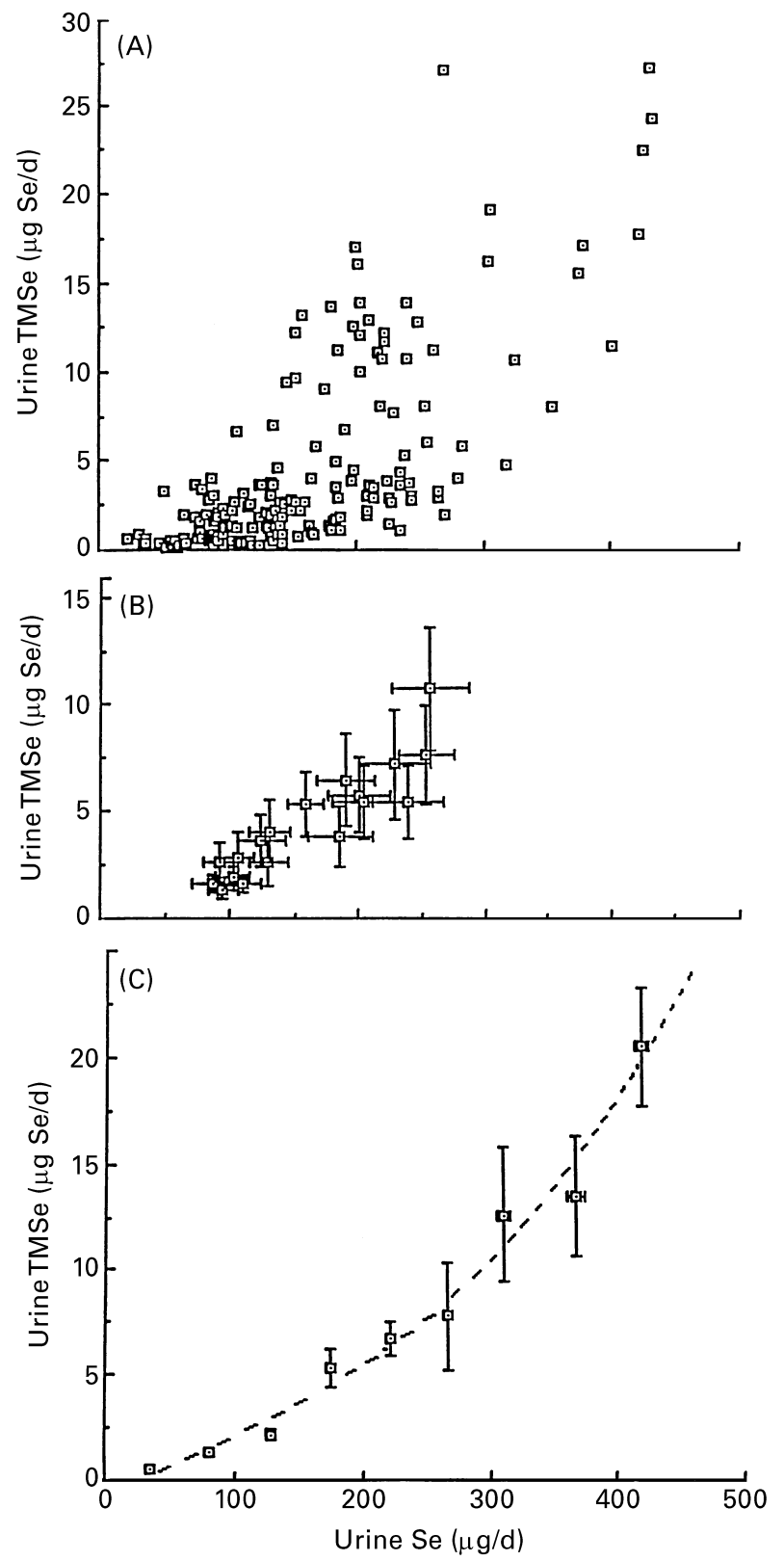

Fig. 4. The observed relationship between urine trimethylselenonium (TMSe) and urine Se excretion in male subjects $(n 10)$ with high longterm Se intakes. Samples were collected over a $70 \mathrm{~d}$ period whilst subjects were receiving a diet containing $30-45 \mu \mathrm{g} \mathrm{Se} / \mathrm{d}$, and were given an intravenous infusion of $105 \mu \mathrm{g}$ Se as selenite on day 0 , and $113 \mu \mathrm{g}$ Se on day 62. (A) Individual data for all urine samples; (B) group data for each day of the protocol; (C) group data according to $50 \mu \mathrm{g}$ increments in urine Se: the relationship between urine TMSe and urine $\mathrm{Se}$ is described by the equation TMSe $=-0.934+$ $\left(3.22 \times 10^{-2}\right) \mathrm{Se}-\left(3.59 \times 10^{-5}\right) \mathrm{Se}^{2}+\left(1.78 \times 10^{-7}\right) \mathrm{Se}^{3}$ (r 0.989). Standard errors of the mean are represented by vertical and horizontal bars.

(Fig. 4(C)), the non-linear relationship between urine TMSe and urine Se becomes clearer. If the polynomial expression given in Fig. 4(C) is accepted to represent the experimental data, then the slope of the relationship at $100 \mu \mathrm{g}$ Se excretion per day in urine is $0.030(\mu \mathrm{g} \mathrm{TMSe} / \mu \mathrm{g}$ Se), while the corresponding slope at $300 \mu \mathrm{g}$ Se excretion per day in urine 

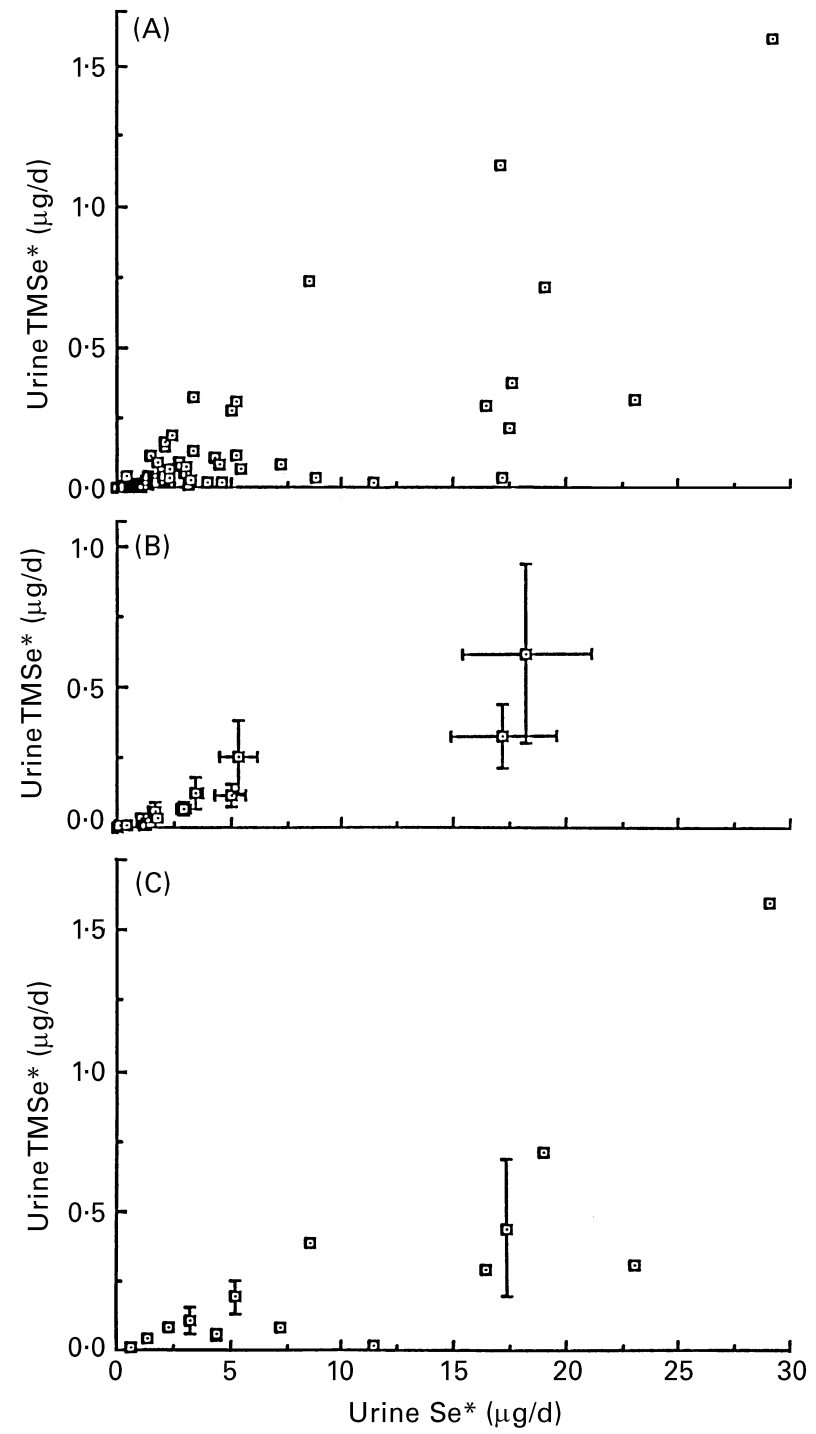

Fig. 5. The observed relationship between urine $\left[{ }^{74}\right.$ Se]trimethylselenonium $\left(\mathrm{TMSe}^{*}\right)$ and urine $\left[{ }^{74} \mathrm{Se}\right]$ selenium $\left(\mathrm{Se}^{*}\right)$ excretion in male subjects $(n 5)$ with high long-term selenium intakes. Complete $24 \mathrm{~h}$ urine collections were made daily for the first $7 \mathrm{~d}$, and then on days 22 , 43 and 62 following an infusion of $105 \mu \mathrm{g}$ Se labelled with ${ }^{74}$ Se on day 0 , and then daily for $7 \mathrm{~d}$ following a second infusion of $113 \mu \mathrm{g} \mathrm{Se}$ labelled with ${ }^{74} \mathrm{Se}$ on day 64 (total of five urine samples). Subjects were receiving a diet containing $30-45 \mu \mathrm{g} \mathrm{Se} / \mathrm{d}$. (A) Individual data for all five urine samples; (B) group data for each day of the protocol; (C) group data according to $1 \mu \mathrm{g}$ increments in urine $\mathrm{Se}^{*}$. Standard errors of the mean are represented by vertical and horizontal bars.

is 14.4 ( $\mu \mathrm{g} \mathrm{TMSe} / \mu \mathrm{g} \mathrm{Se})$. This indicates a large increase in TMSe excretion with increase in urine Se as long-term intake is increased.

\section{Relationship between labelled urine selenium and urine trimethylselenonium}

The data showing the relationship between urine excretion of labelled Se (urine $\mathrm{Se}^{*}$ ) and its TMSe component (TMSe*) are given in Fig. 5. The data are presented in the same general format as in Fig. 4 for chemically measured Se. Data given in Fig. 5(C) show that similarly to the
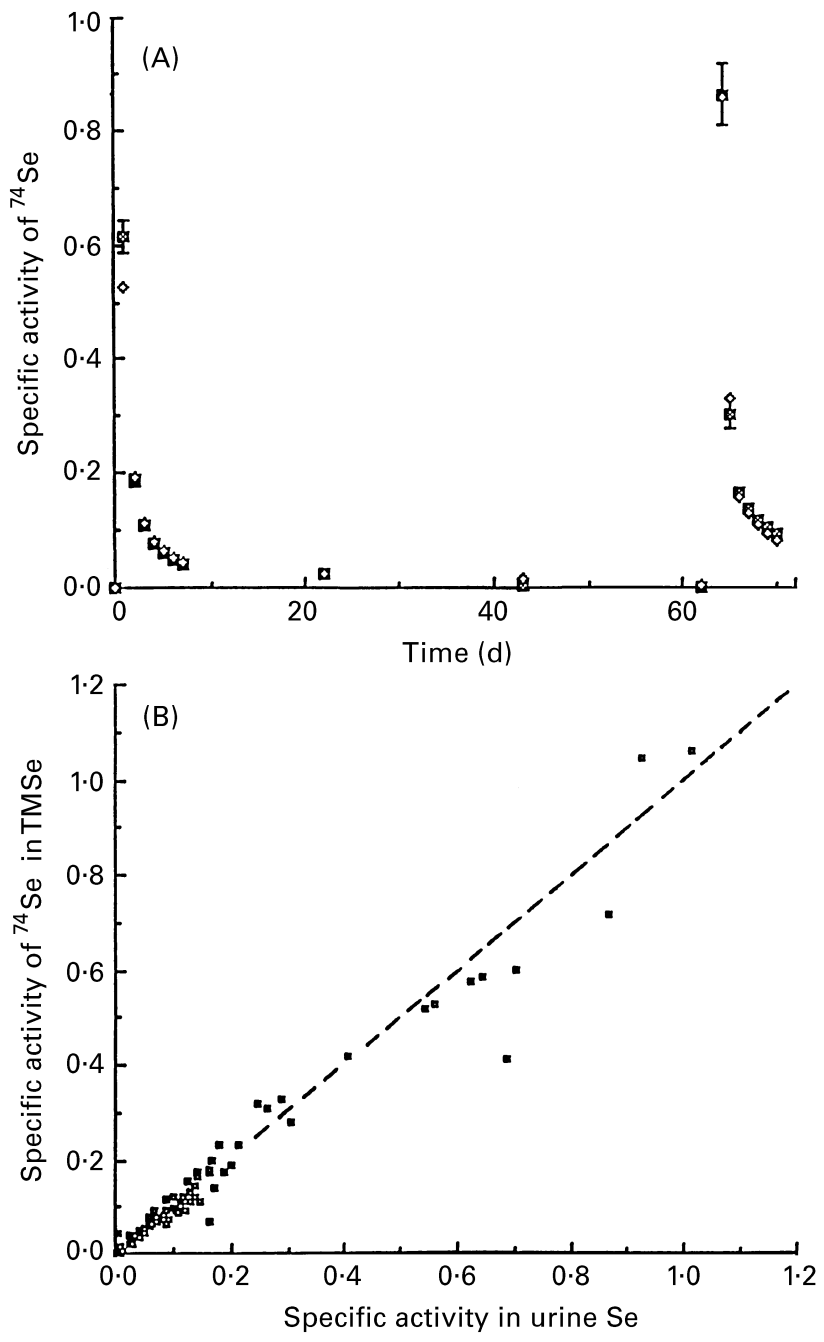

Fig. 6. (A) Specific activity of ${ }^{74} \mathrm{Se}$ in urine Se ( $\square$ ) and urine trimethylselenonium (TMSe; $(\diamond)$ ) during the $70 \mathrm{~d}$ study period and (B) the observed correlation between the specific activity of ${ }^{74} \mathrm{Se}$ in urine Se $(\boldsymbol{\square})$ and in urine TMSe $(\diamond)$. Subjects (male, $n 5$ ) had high long-term selenium intake, and received a diet containing 30-45 $\mu \mathrm{g}$ $\mathrm{Se} / \mathrm{d}$ during the $70 \mathrm{~d}$ study period. Subjects received an intravenous infusion of $105 \mu \mathrm{g}$ Se labelled with ${ }^{74}$ Se, as selenite, on day 0 and a second infusion of $113 \mu \mathrm{g}$ Se labelled with ${ }^{74} \mathrm{Se}$, as selenite, on day 64. Standard errors of the mean are represented by vertical bars. --- , Line of identity for observed correlation.

corresponding data for chemically measured Se (Fig. 4(C)) the relationship between urine $\mathrm{TMSe}^{*}$ and urine $\mathrm{Se}^{*}$ also appears to be non-linear, with the slope increasing as long-term Se intake is increased.

\section{Relationship of specific activities for urine selenium and trimethylselenonium}

The specific activity (SA) for each sample (urine Se or urine TMSe) was calculated as $\mathrm{R}_{74 / 77}: \mathrm{R}^{\circ}{ }_{74 / 77}$, which corresponds to the ${ }^{74} \mathrm{Se}^{*}:{ }^{77} \mathrm{Se}^{\circ}$ ratio. The value of $\mathrm{R}^{\circ}{ }_{74 / 77}$ was obtained by averaging all available data from baseline samples. The observed relationship between specific activities of urine $\mathrm{Se}$ and urine TMSe are shown in Fig. 6. In Fig. 6(A), we have plotted average ( \pm 1 SEM) SA for daily urine for all subjects 
for whom SA data are available for the entire course of the experiment. In Fig. 6(B), we have shown the observed correlation between the two SA for all urine samples analysed. The data indicate that SA of urine Se was not significantly different from the corresponding value for urine TMSe.

\section{Discussion}

Se supplementation studies conducted recently with residents of the USA (Clark et al. 1996) have provided further evidence for chemopreventive potency of long-term $\mathrm{Se}$ supplementation against several types of cancer (Patterson \& Levander, 1997). Despite this potentially important observation, current knowledge about the relationship between several variables of Se supplementation, its chemopreventive efficacy, and the potential for toxicity is not sufficiently defined to permit use of Se-supplements for long-term purposes (Patterson \& Levander, 1997) with subjects consuming nutritionally adequate levels of this trace element (Combs \& Combs, 1986).

In order to elucidate the long-term effects of Sesupplements on chemopreventive efficacy the tissue flux of biologically active selenocompounds generated from the increased body Se content needed to be investigated (Janghorbani et al. 1990). Current knowledge about metabolism of Se in human subjects (Sunde, 1990) indicates that the most likely candidate(s) result from generation of the labile selenocompound, $\mathrm{Se}^{2-}$ (Sunde, 1990; Ip et al. 1991; Vadhanavikit et al. 1993). As noted earlier, the currently accepted relationship between various chemical forms of $\mathrm{Se}$ in the body and $\mathrm{Se}^{2-}$ is shown in the simplified scheme of Fig. 1. According to this scheme, body Se consists of two metabolically distinct pools: Semet, which can be substituted non-specifically for methionine in body proteins, and a selenite-exchangeable metabolic pool (Janghorbani et al. 1990). Dietary or supplemental Se is added to both pools depending on its chemical forms and methionine status of the subject (Waschulewski \& Sunde, 1988; Sunde, 1990). While the selenite-exchangeable metabolic pool interacts reversibly with $\mathrm{Se}^{2-}$ the Semet pool only generates $\mathrm{Se}^{2-}$. At steady state, there is an average whole body half-life of $102 \mathrm{~d}$ for the selenite-exchangeable metabolic pool and $252 \mathrm{~d}$ for Semet (Patterson \& Levander, 1997). The turnover characteristics of the two pools are primarily determined by the chemical form consumed (Waschulewski \& Sunde, 1988). The steady-state Se content of the selenite-exchangeable metabolic pool is probably at its saturation level in subjects who consume a nutritionally adequate amount of $\mathrm{Se}$ (Thomson \& Robinson, 1980) as is the case for healthy North Americans (Combs \& Combs, 1986; National Research Council, 1989). In contrast, the steady-state Se content of Semet is directly proportional to daily consumption of Semet.

$\mathrm{Se}^{2-}$ is either utilized for synthesis of constituents of the selenite-exchangeable metabolic pool such as the glutathione peroxidases (Sunde, 1990, 1997), selenoprotein P (Burk \& Hill, 1993) selenoprotein W (Vendeland et al. 1995), and iodothyronine deiodinases (Sunde, 1997), or is excreted, and does not accumulate in the body. Two known excretory products are dimethyl selenide and TMSe (Ip et al. 1991; Vadhanavikit et al. 1993) which are expired in air (Hsieh \& Ganther, 1977) or excreted in urine (Sun et al. 1987) respectively.

As seen from the data of Fig. 2, the relationship between urine $\mathrm{Se}$ and the estimated long-term $\mathrm{Se}$ intake is more linear than that for TMSe over the entire range of intake. This may indicate that other excretory pathways in addition to TMSe play increasingly significant roles in eliminating excess catabolized-tissue Se. In light of the quantitative significance of respiratory dimethyl selenide under subtoxic-to-toxic intakes (Hsieh \& Ganther, 1977), this pathway may account for some of the non-linearity observed in urine Se (or TMSe) at the high end of long-term Se intake in our subjects. This non-linearity appears to hold not only for data obtained during the initial $7 \mathrm{~d}$ following dietary Se restriction (Fig. 2), but also for data obtained for days 22, 43, and 62 (Fig. 2), indicating possibly that even after approximately an initial month of dietary Se restriction, non-urine excretion may still be an important loss pathway in our subjects. Furthermore, the value of the ratio of daily urine Se excretion for the latter days (average value for days 22, 43, and 62; Fig. 2) to the corresponding value for the initial days (average value for days $2-7$; Fig. 2) appeared to be independent of long-term Se intake in our subjects (average for all subjects: 0.462 (SEM 0.023)). The same was also true for TMSe excretion (average ratio for all subjects: 0.437 (SEM 0.073)). One interpretation for this observation is that whole-body turnover of $\mathrm{Se}$ in these subjects was not affected by the 1-2 month dietary Se restriction of our experiment.

Urinary Se and TMSe excretion did not differ during the first $7 \mathrm{~d}$ after the life-long high exposure to Se (Fig. 3(A) and (B) days 2-7). However, after the dose of labelled-Se at day 64, both Se and TMSe excretion declined during the following $7 \mathrm{~d}$ (days 64 to 71 ). This suggests that enough body Se had been depleted to affect the excretion of urinary $\mathrm{Se}$ and TMSe.

Data given in Figs. 4 and 5 indicate the possible nonlinear relationship between urine TMSe and urine Se, both for TMSe arising from catabolism of endogenous body $\mathrm{Se}$ (Fig. 4) and that from infused selenite (Fig. 5). Data shown in Fig. 4(C), and to a lesser extent also Fig. 5(C), show that the major determinant of this non-linear relationship is perhaps the flux of $\mathrm{Se}^{2-}$ generated from catabolism of body selenocompounds, and other subject-specific factors may play a more minor role. However, even in subjects with very high long-term Se intake urine TMSe still constitutes a quantitatively small fraction of urine Se. Therefore, the combination of the two observations that: (1) rate of urine excretion of Se decrease per unit increase in long-term Se intake, and (2) TMSe and urine Se are non-linearly related, indicate that either urine Se or urine TMSe alone may not provide a linear representation of whole body flux of $\mathrm{Se}^{2-}$. It may be that the combination of TMSe excretion in urine and dimethyl selenide in expired air provides the most quantitatively accurate measure of whole body $\mathrm{Se}^{2-}$ flux and thus the most accurate measure of the ability of whole body Se to maintain tissue fluxes of biologically active Se for chemopreventive purposes. The validity of this hypothesis needs further exploration.

Finally, the nearly identical SA observed for urine Se and 
its TMSe component (Fig. 6) indicate the very close precursor-product relationship for these two components. This may indicate that most urine Se is related to methylation pathway of tissue $\mathrm{Se}^{2-}$. Equally importantly, this may also indicate identical metabolism of infused selenite and catabolized endogenous Se. If this is the case, urine excretion of infused labelled-selenite may also provide as satisfactory a means for monitoring whole body flux of endogenous $\mathrm{Se}^{2-}$ as endogenously produced TMSe, or urine Se.

\section{Acknowledgements}

The experimental work reported here was supported by Public Health Service grant number DK 38341 from the National Institute of Arthritis, Diabetes and Digestive and Kidney Diseases to Oregon State University (P. D. W.).

\section{References}

Burk RF \& Hill KE (1993) Regulation of selenoproteins. Annual Review of Nutrition 13, 65-81.

Burk RF \& Hill KE (1994) Selenoprotein P. A selenium-rich extracellular glycoprotein. Journal of Nutrition 124, 1891-1897.

Burk RF, Hill KE, Read R \& Bellew T (1991) Response of rat selenoprotein $\mathrm{P}$ to selenium administration and fate of its selenium. American Journal of Physiology 261, E26-E30.

Combs GF \& Combs SB (1986) The Role of Selenium in Nutrition. New York, NY: Academic Press.

Clark LC, Combs GF, Turnbull BW, Slate EH, Chalker DK, Chow J, Davis LS, Glover RA, Graham GF, Gross EG, Krongrad A, Lesher JL, Park HK, Sanders BB, Smith CL \& Taylor JR (1996) Effects of selenium supplementation for cancer prevention in patients with carcinoma of the skin. Journal of the American Medical Association 276, 1957-1963.

Deagen JT, Beilstein MA \& Whanger PD (1991) Chemical forms of selenium in selenium containing proteins from human plasma. Journal of Inorganic Biochemistry 41, 261-268.

Deagen JT, Butler JA, Zachara BA \& Whanger PD (1993) Determination of the distribution of selenium between glutathione peroxidase, selenoprotein $\mathrm{P}$, and albumin in plasma. Analytical Biochemistry 208, 176-181.

Hsieh HS \& Ganther HE (1977) Biosynthesis of dimethyl selenide from sodium selenite in rat liver and kidney cell-free systems. Biochimica et Biophysica Acta 497, 205-217.

Ip C , Hayes C, Budnick RM \& Ganther HE (1991) Chemical form of selenium, critical metabolites, and cancer prevention. Cancer
Research 51, 595-600.

Janghorbani M, Martin RF, Kasper LJ, Sam XF \& Young VR (1990) The selenite-exchangeable metabolic pool in humans: a new concept for the assessment of selenium status. American Journal of Clinical Nutrition 51, 670-677.

Levander OA (1987) A global view of selenium nutrition. Annual Review of Nutrition 7, 227-250.

National Research Council (1989) Recommended Dietary Allowances, 10th ed. Washington, DC: National Academy Press.

Patterson BH \& Levander OA (1997) Naturally occurring selenium compounds in cancer chemoprevention trials: a workshop summary. Cancer Epidemiology Biomarkers and Prevention 6, 6369.

Sun XF, Ting BTG \& Janghorbani M (1987) Excretion of trimethylselenonium ion in human urine. Analytical Biochemistry 167, 304-311.

Sunde RA (1990) Molecular biology of selenoproteins. Annual Review of Nutrition 10, 451-474.

Sunde RA (1997) Selenium. In Handbook of Nutritionally Essential Mineral Elements, pp. 493-556 [BL O’Dell and RA Sunde, editors]. New York, Basel, Hong Kong: Marcel Dekker, Inc.

Ting BTG, Mooers CS \& Janghorbani M (1989) Isotopic determination of selenium in biological materials with inductively coupled plasma mass spectrometry. Analyst 114, 667-674.

Thomson CD \& Robinson MF (1980) Selenium in human health and disease with emphasis on those aspects peculiar to New Zealand. American Journal of Clinical Nutrition 33, 303-323.

Vadhanavikit S, Ip C \& Ganther HE (1993) Metabolites of sodium selenite and methylated selenium compounds administered at cancer chemoprevention levels in the rat. Xenobiotica 23, 731745.

Vendeland SC, Beilstein MA, Yeh J-Y, Ream RM \& Whanger PD (1995) Rat skeletal muscle selenoprotein W: cDNA clone and mRNA modulation by dietary selenium. Proceedings of the National Academy of Sciences USA 92, 8749-8753.

Waschulewski IH \& Sunde RA (1988) Effect of dietary methionine on utilization of tissue selenium from dietary selenomethionine for glutathione peroxidase in the rat. Journal of Nutrition 118, 367-374.

Xia Y, Zhao X, Zhu L \& Whanger PD (1992) Distribution of selenium in erythrocytes, plasma, and urine of Chinese men of different selenium status. Journal of Nutritional Biochemistry $\mathbf{3}$, 211-216.

Yang G, Zhou R, Yin S, Gu L, Yan B, Liu Y, Liu Y \& Li X (1989) Studies of safe maximum dietary Se intake in a seleniferous area in China. I. Selenium intake and tissue selenium levels of the inhabitants. Journal of Trace Elements and Electrolytes in Health and Disease 3, 77-87. 